\title{
Flood risk mitigation in Europe: how far away are we from the aspired forms of adaptive governance?
}

\author{
Marie Fournier $^{1}$, Corinne Larrue $^{2}$, Meghan Alexander $^{3}$, Dries Hegger $^{4}$, Marloes Bakker $^{4}$, Maria Pettersson $^{5}$, Ann Crabbé $^{6}$, \\ Hannelore Mees 6 and Adam Chorynski ${ }^{7}$
}

\begin{abstract}
Flood mitigation is a strategy that is growing in importance across Europe. This growth corresponds with an increasing emphasis on the need to learn to live with floods and make space for water. Flood mitigation measures aim at reducing the likelihood and magnitude of flooding and complement flood defenses. They are being put in place through the implementation of actions that accommodate (rather than resist) water, such as natural flood management or adapted housing. The strategy has gained momentum over the past 20 years in an effort to improve the sustainability of flood risk management (FRM) and facilitate the diversification of FRM in the pursuit of societal resilience to flooding. Simultaneously, it is increasingly argued that adaptive forms of governance are best placed to address the uncertainty and complexity associated with social-ecological systems responding to environmental challenges, such as flooding. However, there have been few attempts to examine the extent to which current flood risk governance, and flood mitigation specifically, reflect these aspired forms of adaptive governance. Drawing from EU research into flood risk governance, conducted within the STAR-FLOOD project, we examine the governance of flood mitigation in six European countries: Belgium, England, France, the Netherlands, Poland, and Sweden. Using in-depth policy and legal analysis, as well as interviews with key actors, the governance and implementation of flood mitigation in these countries is evaluated from the normative viewpoint of whether, and to what extent, it can be characterized as adaptive governance. We identify five criteria of adaptive governance based on a comprehensive literature review and apply these to each country to determine the "distance" between current governance arrangements and adaptive governance. In conclusion, the flood mitigation strategy provides various opportunities for actors to further pursue forms of adaptive governance. The extent to which the mitigation strategy is capable of doing so varies across countries, however, and its role in stimulating adaptive governance was found to be strongest in Belgium and England.
\end{abstract}

Key Words: adaptive governance; climate change; country comparison; European Union; flood; mitigation; risk

\section{INTRODUCTION}

The need to enhance societal resilience to natural hazards has been widely acknowledged in both national and international policy agendas and scientific research over the past 20 years (Walker et al. 2004, Folke et al. 2005, UNISDR 2005, Folke 2006, Davoudi et al. 2012). However, even though there are large differences in physical circumstances in different countries, which will influence the technical feasibility of measures, there has been a discernible shift in the resilience discourse from an emphasis on hazard prevention and rapid recovery toward an increasing recognition of the need to adapt and transform (Folke et al. 2005, Pahl-Wostl et al. 2007, Mostert et al. 2008, Raadgever et al. 2008, Folke et al. 2010). In the context of flood risk management (FRM), this is reflected in the transition from defense-dominated approaches toward the diversification of risk management strategies to address risk holistically (Aerts et al. 2008, Innocenti and Albrito 2011, Hegger et al. 2014). Arguably, this diversified approach enhances societal resilience by addressing multiple aspects of risk (i.e., exposure, hazard, and vulnerability), thus reducing reliance on defense and creating layers of contingencies should certain defense measures fail.

In this context, the notion of flood mitigation has emerged in flood risk management discourse as part of a set of strategies. First, the notion of mitigation was driven by the environmental movement and sustainability discourse. It has since become embodied within the notion of risk and adaptation, based on the argument that a diversified suite of strategies is required. The term itself is a fuzzy concept, and it is also often poorly defined. Hegger et al. (2014) offered conceptual clarity, defining mitigation as a strategy for minimizing the likelihood and magnitude of flooding through the implementation of measures that aim to accommodate water. These types of measures accommodate water both horizontally and vertically: in certain designated areas, water is allowed to enter, with the consequence that the water level of threatening water bodies (e.g., large rivers) may be lowered. Although the outcome of such measures is akin to those implemented in defense strategies, rather than acting to resist and constrain water (for example, by using flood walls or embankments), mitigation measures employ a different approach. Included within the strategy are methods such as flood storage areas, forms of sustainable urban drainage, and the approaches used in natural flood management, such as wetland creation, the restoration of river corridors, and tree planting (DEFRA/EA 2014), as well as property level measures, such as air brick covers, flood gates, or flood resilient buildings. The definition proposed by Hegger et al. establishes clear boundaries for the notion of mitigation and distinguishes it from other FRM strategies, and we have therefore adopted it here.

Research conducted in the context of the STAR-FLOOD project, EU's $7^{\text {th }}$ framework program, has revealed that mitigation is an

\footnotetext{
${ }^{1}$ Laboratoire Géomatique et Foncier, Conservatoire National des Arts et Métiers, Ecole Supérieure des Géomètres et Topographes, ${ }^{2}$ Paris School of Planning, Lab'Urba, Paris Est University, ${ }^{3}$ Sustainability Research Institute, School of Earth and Environment, University of Leeds, ${ }^{4}$ Environmental Governance, Copernicus Institute of Sustainable Development, Utrecht University, ${ }^{5}$ Department of Business Administration, Technology and Social Sciences, Luleå University of Technology, ${ }^{6}$ Research Group Society and Environment, University of Antwerp, ${ }^{7}$ Institute for Agricultural and Forest Environment, Polish Academy of Sciences
} 
emergent and expanding strategy in Belgium, England, France, the Netherlands, Poland, and Sweden (Alexander et al. 2016, Ek et al. 2016, Kaufmann et al. 2016, Larrue et al. 2016, Matczak et al. 2016 Mees et al. 2016). An important driving factor behind this change is increasing recognition that flood defense is not necessarily the most financially or environmentally sustainable strategy in the long term. Aligned to this, there has been a discernible discursive shift from keeping the water out through dikes, dams, and embankments, to a realization that to some extent it is necessary to learn to live with floods, and that it might be more useful to try to accommodate water through flood mitigation.

Although flood mitigation is clearly emerging as a FRM strategy in its own right, there has been little research to date that examines how this strategy has been assimilated within flood risk governance arrangements.

Calls for adaptive modes of governance are also apparent in the literature (Cosens and Williams 2012, Chaffin et al. 2014) in which the notion of adaptation has become attached to discussions of vulnerability and resilience. Indeed, enhancing adaptive capacity is often regarded as a means of reducing vulnerability or enhancing resilience (Adger et al. 2005, Brooks et al. 2005, Gallopín 2006, Smit and Wandel 2006). Resilience remains a heavily contested term between engineering, ecological, and social-ecological schools of thinking (Walker et al. 2004, Folke et al. 2005, Folke 2006). Adaptive capacity is embedded in the concept of resilience in the latter perspective (Adger 2006). To be deemed truly resilient, social-ecological systems cannot simply return to normal or merely persist after a stressful event, but instead need to adjust, learn, and evolve in the step toward a more desirable resilient state (Walker et al. 2004, Folke et al. 2010). Thus adaptability and transformability are commonly conceived as processes or outcomes enabling a social system to cope and adjust to changing conditions (Smit and Wandel 2006, Folke et al. 2010).

Within the school of resilience thinking, resilience, adaptability, and transformability are viewed as three closely intertwined concepts, whereby transformability in the short term is seen as being conducive to long term resilience (Folke et al. 2010). This stance on resilience thinking has been adopted in the STARFLOOD project. From a governance perspective, this research sought to understand the ways in which arrangements of flood risk governance supported or constrained capacities to adapt, as well as societal resilience more broadly. Taking this one step forward, we reflect critically on the extent to which capacities to adapt are supported through adaptive forms of flood risk governance; in short, adopting the position that adaptation and adaptive capacity require traits of adaptive governance to be established (e.g., mechanisms for learning). In turn, this raises implications for enhancing societal resilience to flooding in the future.

Adaptive governance is defined by Cosens and Williams (2012) as a governance process whereby multiactor collaboration and coordination at multiple scales provides the necessary feedback mechanisms to inform appropriate responses to environmental challenges. This has been widely applied to the study of socialecological systems and resilience research (e.g., Chaffin et al. 2014). In the context of risk uncertainty and the complexity associated with contemporary social-ecological systems, adaptive governance is increasingly seen as a necessary step forward. However, there have been few attempts to examine the extent to which current flood risk governance in general, and flood mitigation in particular (Brody et al. 2009), reflect desirable forms of adaptive governance.

We intend to address this knowledge gap. By adopting the normative stance that adaptive governance is beneficial for addressing the growing risks and uncertainties of flooding, we present a framework for assessing the extent to which current arrangements for governing flood mitigation reflect features of adaptive governance. Drawing from the extensive literature in this field, five sensitizing concepts of adaptive governance have been identified to inform a qualitative evaluation. By determining the conceptual distance between current arrangements governing flood mitigation in six European countries (Belgium, England, France, the Netherlands, Poland, and Sweden) and adaptive governance, our comparative focus aims to highlight the current constraints and opportunities relating to the development of more adaptive forms of flood mitigation governance in Europe.

\section{METHODS}

We draw from cross-disciplinary research conducted in the context of the EU-FP7 funded STAR-FLOOD project, which examined the role of flood risk governance in enhancing societal resilience to flooding in six European countries: Belgium, England, France, the Netherlands, Poland, and Sweden. Flood risk governance in these countries has evolved in different cultural, socioeconomic, political, and flood risk contexts (Hegger et al. 2013), thus providing a unique opportunity to examine how flood mitigation governance has emerged under differing conditions.

On the basis of an extensive literature review of adaptive governance and a collation of academic and gray literature, a series of criteria was identified to inform a qualitative-based evaluation framework. This was applied to each selected country to determine the extent to which current flood mitigation governance reflects features of adaptive governance, and in turn, identify the factors supporting or constraining adaptive governance.

Semistructured interviews with key actors involved in the governance and implementation of flood mitigation were carried out in the selected countries. A technique of range sampling was employed to ensure that the views and opinions from the full range of actors were represented within in the sample. This was informed by stakeholder mapping (Aligica 2006). What is more, interviewees, related to different types of flood risk management strategies, were selected, depending on the type of flood risk occurring in their country. These interviewees were representatives at the national, regional, or local level. The interviewees were furthermore representative of different types of organization related to state, market, or civil society. The analysis is therefore partially based on the views expressed by policymakers and practitioners operating at all spatial scales, e.g., public operating authorities, local tiers of government, water companies, and relevant governmental departments. Participants were questioned on flood risk governance in general, but this also led to important insights into flood mitigation and its relationship with adaptive governance. In particular, the perceived effectiveness of mitigation was discussed, as well as the strengths 
and weaknesses of the current approach and other themes typically associated with adaptive governance, such as opportunities for learning. This was accompanied by an extensive desk-based analysis of the relevant policies and legal frameworks to identify the formal and informal rules, as well as the discursive trends that are shaping the governance of flood mitigation. Together with the results of this desk research, a representative picture of flood governance in each country was achieved.

\section{ANALYTICAL FRAMEWORK FOR IDENTIFYING TRAITS OF ADAPTIVE GOVERNANCE}

The notion of adaptive governance has emerged over the past 10 years (Chaffin et al. 2014), arguably driven by the recognition that centralized governance through top-down directives or command-and-control policies is inadequate for addressing the complexities and uncertainties that characterize social-ecological systems (Chaffin et al. 2014). Numerous authors have also reflected on the importance of bottom-up, community-led initiatives and citizens' involvement in environmental decision making (Weber 2003, Brosius et al. 2005).

Literature provides several definitions of adaptive governance and adaptive management. Indeed, scholars have also focused on adaptive management or adaptive comanagement experiments, which are closely linked to the concept of adaptive governance. Boyle et al. (Boyle et al. 2001:122, as cited in Cosens and Williams 2012) explained the distinction between adaptive governance and adaptive management: "governance is the process of resolving trade-offs and of providing a vision and direction for sustainability, management is the operationalization of this vision." Adaptive management therefore refers to concrete proposals and solutions deriving from an adaptive governance process. The criteria selected address both concepts. Gunderson and Light (2006) explained that adaptive management is a critical component of adaptive governance that enables us to focus on certain issues that might otherwise be missed, such as learning processes and capacities to deal with uncertainties.

Huitema et al. (2009) summarized the key characteristics of adaptive governance and management. These include notions of polycentricity, evidence of public participation, experimental approaches to resource management, and management at a bioregional scale to match the scale of the problem (as opposed to relying on administrative boundaries).

When defining adaptive governance, scholars often point at one major feature: adaptive governance processes are multilevel and facilitate cooperation among different types of institutions. Cosens and Williams (2012) explained that adaptive governance shifts the focus from pursuits of efficiency and encourages "diversity, redundancy, and multiple levels of management that include local knowledge and local action." Thus, adaptive governance requires collaboration and cooperation across different levels of governmental, nongovernmental, and individual action. Dietz et al. (2003) also established a clear connection between adaptive governance approaches and the involvement of the various stakeholders. Adaptive governance facilitates deliberative approaches, including a dialogue among resource users. These approaches are often multilevel and complex, and the gather very different varieties of institutions (mixed types, such as market- and state-based). For Folke et al. (2005:449), "adaptive governance of ecosystems [...] involves local, as well as higher, organizational levels and aims at finding a balance between decentralized and centralized control." Multilevel governance is a recurring theme in the literature, and is therefore identified as an initial key criterion for our framework.

Public participation is another recurring theme. For instance, Folke et al. (2005) explained how adaptive governance involves "the devolution of management rights and power sharing that promotes participation" (Folke et al. 2005:449). Taking this further, when defining adaptive management, scholars advocate the importance of "flexible community-based systems of resource management" (Folke et al. 2005:448). Therefore, the second criterion to be used to assess the characteristics of mitigation strategy in the six countries refers to public participation and will focus more specifically on the possibilities proposed by the institutional stakeholders for public participation.

Further research on adaptive management provides an additional third criterion for analyzing flood mitigation: the capacity to propose tailor-made solutions to deal with local issues. Indeed, scholars have shown that adaptive management enables the definition of tailor-made solutions. For Folke et al. (2005), for example, adaptive management systems are "tailored to specific places and situations" (Folke et al. 2005:448). Authors have also noted that adaptive management is characterized by the capacity to adapt and be flexible when it comes to changing situations. Brody at al. (2009:913-914) wrote that local level policymakers must be able to adapt to changing environmental conditions, shifts in political interests and objectives, or new and often ambiguous information. To them, "Flood risk mitigation plans and policies, from an adaptive management perspective, must be flexible instruments geared toward varying levels of uncertainty and surprise." Thus, our third criterion focuses on flexibility in governance arrangements and assesses to what extent they enable tailor-made mitigation measures.

The fourth criterion is concerned with the extent to which governance supports flood management at the appropriate scale; where "appropriate" is defined in terms of the hydrological and hydraulic scale of the problem, as opposed to administrative units. This can vary according to different types of flooding. For instance, whereas the catchment scale is advocated for fluvial flood management, pluvial or surface water flooding is typically highly localized and may require a localized approach. Moreover, in areas exposed to multiple sources of flooding, a combination of different scale-based approaches may be required. From a governance perspective, there is a need to examine the extent to which flood mitigation is delivered at the appropriate scale(s) by responsible actors and coordination therein.

Last, Cosens and Williams (2012) also defined adaptive management as "an approach designed to address the inherent uncertainties in a system's response to management changes." As a fifth element, therefore, the literature on adaptive governance focuses on the capacity of these processes to learn from experimentation, to draw knowledge from it, and to adapt the proposals that emerge from it. Dietz et al. (2003) wrote that adaptive governance is largely based on learning processes and the ability of stakeholders and institutions to adapt within institutional designs that facilitate experimentation, learning, and change. This ability to learn from previous experiments is also a 
Table 1. Conceptual framework for analyzing flood mitigation through the lens of adaptive governance.

\begin{tabular}{|c|c|c|}
\hline \# & Criteria of adaptive governance & References \\
\hline I & $\begin{array}{l}\text { Multilevel governance, with a balance between top-down and bottom-up decision } \\
\text { making }\end{array}$ & $\begin{array}{l}\text { Dietz et al. } 2003 \\
\text { Gunderson and Light } 2006 \\
\text { Huitema et al. } 2009\end{array}$ \\
\hline II & Multiactor (formal and informal) networks, including active participation from citizens & $\begin{array}{l}\text { Folke et al. } 2005 \\
\text { Huitema et al. } 2009\end{array}$ \\
\hline III & $\begin{array}{l}\text { Flexibility in governance arrangements enabling mitigation measures tailored to local } \\
\text { conditions }\end{array}$ & Folke et al. 2005 \\
\hline IV & $\begin{array}{l}\text { Governance arrangement supports management at the appropriate scale of the problem } \\
\text { (e.g., fluvial FRM should be managed according to hydrological scales, i.e., on a } \\
\text { catchment basis, as opposed to administrative units) }\end{array}$ & Folke et al. 2005 \\
\hline V & Opportunities for experimentation and social and institutional learning & $\begin{array}{l}\text { Cosens and Williams } 2012 \\
\text { Huitema et al. } 2009\end{array}$ \\
\hline
\end{tabular}

key characteristic of adaptive management. For scholars working on this concept, it is important to highlight how policymakers learn not only from previous policies, but also from past events. Their actions are based on the principles of scientific experimentation and try to aggregate and reconcile a plurality of interests and influences, rather than a single expert or individual (Brody et al. 2009). Learning is often initiated through a process of monitoring responses to a particular action and subsequent incremental changes based on the lessons learnt (Cosens and Williams 2012). Therefore, capacities for learning are identified as the fifth criterion for assessing adaptive governance. These have been assessed by exploring the extent to which learning possibilities were recognized by the actors that we interviewed.

Based on this literature review, the governance arrangements underpinning the implementation of flood mitigation will be analyzed in the following sections using the five criteria summarized in Table 1.

\section{FLOOD MITIGATION GOVERNANCE IN SIX COUNTRIES}

Flood mitigation is a strategy that has developed to different degrees in the countries studied in the STAR-FLOOD project. This strategy is delivered through a range of measures (as summarized in Table 2).

Today, there is a powerful discourse in all studied countries that encourages the promotion of the types of measures categorized within the mitigation strategy (Hegger et al. 2014). Still, it is possible to make a distinction between countries in which a mitigation strategy has been established for several decades (England), countries in which mitigation has grown in importance over the last 20 years (Belgium, France, the Netherlands), and countries in which it is still emerging (Poland, Sweden).

In England, a diversified approach to FRM has been in existence for approximately 65 years (Alexander et al. 2016). Although mitigation has been established for a considerable period of time, arguably its importance has grown in line with environmental discourses and with the recognition that defenses are not infallible or economically viable in all locations. Natural flood management (such as wetland creation and the restoration of riverside corridors), property-level measures, and sustainable urban drainage systems (SUDS) have been increasingly endorsed to help mitigate the likelihood and magnitude of fluvial, coastal, and surface-water flooding (Pitt 2008, DEFRA/EA 2014).

More recently, mitigation has been growing progressively in importance in Belgium, France, and the Netherlands as a means of addressing the flood issue. Whereas in Belgium, the focus in the past lay on draining redundant water downstream, water managers have been investing significantly in the accommodation of water since the beginning of the 2000s, including through manually controlled flood retention zones and river restoration projects. Moreover, increasing attention has been paid in the past five years to room for water within the urban context through the installation of small-scale retention basins that infiltrate surfaces. It has also been acknowledged, however, that attention to flood mitigation is still insufficiently mainstreamed among spatial planners. For instance, in road building and other areas, there remains a preference for drainage through the sewerage system, even where infiltration would be technically possible.

In France, mitigation measures began to be tested and implemented in earnest at the end of the 1990s, accompanied by a growing understanding that protection systems might fail. Some measures already existed in spatial planning, more precisely in legal planning documents. Since 1995, the state administration has had the opportunity to impose measures to reduce the vulnerability of houses and other constructions in its risk plans (plans de prévention des risques d'inondation (PPRI)), and yet these measures have very rarely been imposed, still less implemented. The first initiatives in the area of vulnerability reduction were mainly launched by municipalities and groups of municipalities during the first decade of this century. Hazardoriented mitigation measures (retention areas, bypasses, and spillways) appeared after these issue-oriented measures. They have tended to be more common in rural areas as a way of accommodating water in areas with a limited number of issues at stake. They are still at an experimental phase in urban areas.

In the Netherlands, a flood defense strategy that applies probability-reducing measures, such as the construction and maintenance of dikes and dunes (dike rings), storm surge barriers, and water storage locations, has historically predominated (Van den Brink et al. 2011, Kaufmann et al. 2016). Still, in the last 20 
Table 2. Main mitigation measures in the six selected countries (sources: Alexander et al. 2016, Ek et al. 2016, Kaufmann et al. 2016, Larrue et al. 2016, Matczak et al. 2016, Mees et al. 2016).

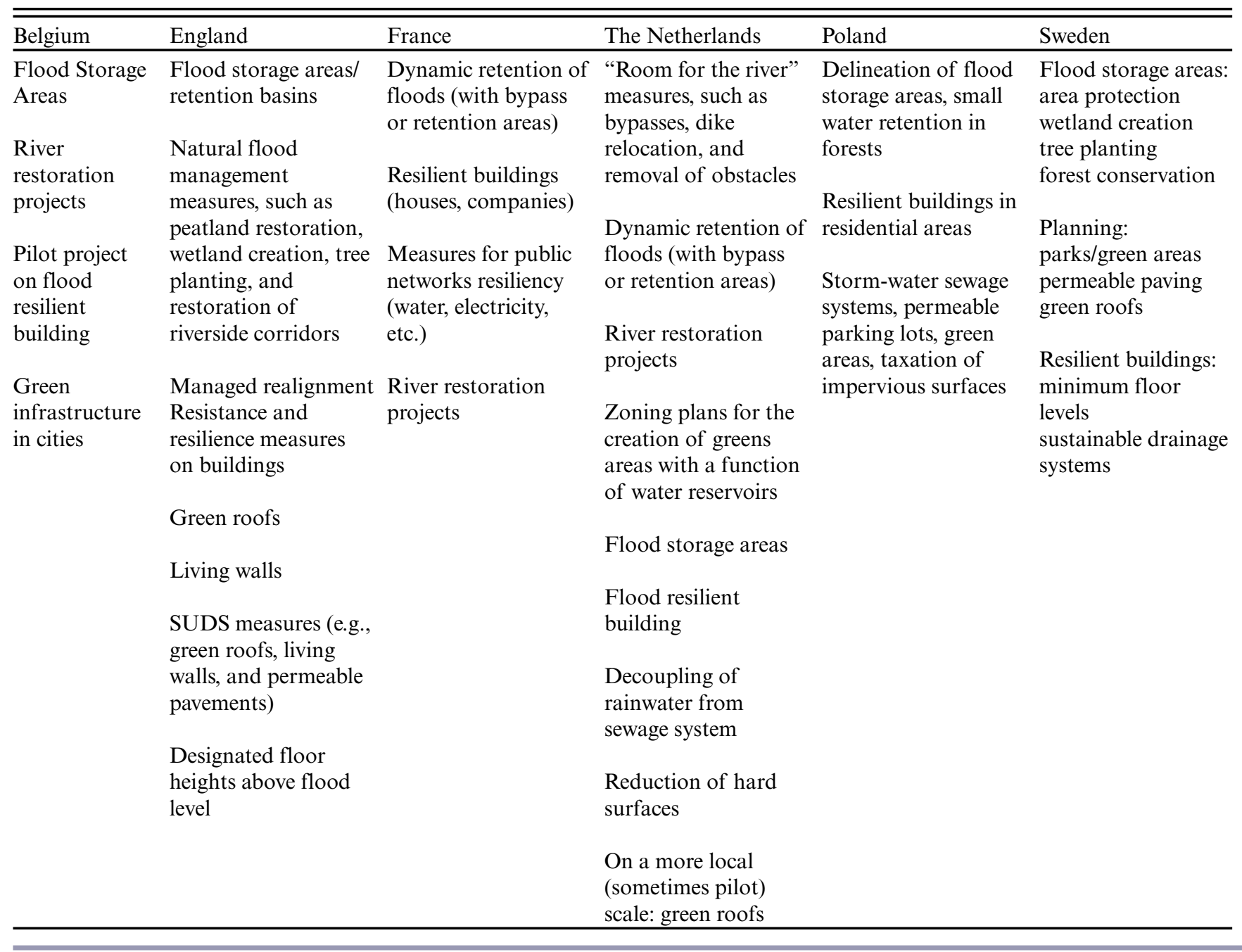

years, consequence-reducing strategies have also become more popular, but they are mostly utilized in exceptional cases, when the flood defense approach is not efficient or feasible, especially as a part of the Room for the River program (Van den Brink et al. 2011, Kaufmann et al. 2016). The only types of flood mitigation measures that are applied nationwide are those used in the context of urban water management. The measures employed by municipalities include actions to decouple rainwater from sewerage systems, including by creating more green spaces in the urban environment or incentivizing residents not to create hard surfaces on their properties (De Graaf et al. 2009). There are also legal frameworks and policy instruments that should enforce actors to take water management into account in spatial decisions. In many legally binding regulations of water authorities, it is prohibited to create hard surfaces (of a certain size), unless the storage capacity will be compensated. The water test must be mentioned here as well. The consequences of every binding spatial planning decision for water management have to be examined and mentioned in the explanatory memorandum of these decisions. In the Netherlands, there is a special legal instrument introduced in the Water Act to facilitate the construction of water storage areas by water authorities. Landowners whose land is designated as a storage area have to tolerate that their land is temporarily used as storage area by the water authority. Other types of measure that have not been mainstreamed but can mainly be found in frontrunner municipalities include rainwater retention through water plazas (Amsterdam and Rotterdam) and green roofs (Rotterdam; Kaufmann et al. 2016). The application of mitigation measures to deal with fluvial flooding or flooding from the sea is being discussed and has been partially implemented in the form of localized niche developments (Kaufmann et al. 2016).

In contrast, in Poland and Sweden, mitigation measures are not implemented within a consistent mitigation strategy. In Poland, the mitigation strategy is not widely represented, but there are several types of actions that can be described as flood risk mitigation. One issue to be taken into account is that this strategy is very often a side effect of a different activity, and the flood 
mitigation effect is reduced as a consequence. One example of this phenomenon is the forest small water retention program, which is used to provide sufficient water for plantations, but also decreases the amounts of water in rivers during flooding. We see quite a similar situation with the flood mitigation measures used in cities: for example, pervious parking lots are built from time to time in Polish towns for mostly economic reasons (a smaller amount of concrete is needed to cover the area) or for visual motives (green infrastructures, such as these, are looked on by decision makers more favorably because they are friendlier than bare asphalt).

Sweden presents a unique case study because flood risk management does not constitute an independent policy area at the national level. Instead, FRM is enveloped within many different policy areas. Measures that traditionally originate in other policy fields can also fulfil flood risk management functions: extensive area protection, afforestation, and park creation. These functions serve environmental and recreational interests as well as flood mitigation services. Measures that aim specifically at a mitigating effect in relation to floods in urban areas may be found in the spatial planning area. They include urban drainage systems and green infrastructures and have recently been expressly incorporated into physical planning and building legislation. In the urban drainage context, pipe networks are still very much prevalent in storm-water management, although new laws have gradually made room for open solutions.

Even though mitigation measures are fairly similar across our selected countries, they have not followed the same path. In some of them, mitigation measures are very normal (England) whereas in others, they have been progressively implemented on a large scale (France), or are only just emerging (Sweden). It is also interesting to note from this brief overview (see table 2), that even though certain measures have been widely implemented in all our countries, others are very country specific, or else are still at an experimental stage. In France, for instance, measures to improve the resilience of cities are still experimental and in Poland they have been realized as a side effect of a different activity, whereas in other countries these measures have been mainstreamed.

\section{HOW DOES THE GOVERNANCE OF MITIGATION IN SIX COUNTRIES REFLECT CHARACTERISTICS OF ADAPTIVE GOVERNANCE?}

\section{Criterion I. Multilevel governance, with a balance between top- down and bottom-up decision making}

As shown in table 3, local actors are being given, and even more commonly are taking on, a role as executors or implementers of mitigation measures in all the studied countries. Municipalities in particular are playing a major part in Belgium, Sweden, France (where Intercommunalités, cooperations among communes, are also becoming increasingly involved), and the Netherlands. Likewise, in England, Lead Local Flood Authorities (LLFAs) have the most responsibilities. In the Netherlands, regional water authorities are also involved in the strategy along with private actors. In Poland, it is mainly private actors who are involved, especially residents.

The countries examined also differ as to the extent in which these local actors are engaging in multilevel governance processes and how these processes can be characterized. In Belgium, the Flanders, Walloon, and Brussels Capital regions as well as provincial governments are also responsible for water retention along watercourses. In addition, they play an important role in creating the right conditions for local governments by providing guidance (for example, the Flemish water test) and by stimulating cooperation at a subbasin scale, such as in the case of river contracts in Wallonia. Similarly, the Environment Agency in the UK maintains a strategic overview of FRM for all types of flooding. In Sweden, too, the situation is characterized by multilevel governance: although measures are all implemented at a local level and involve the municipalities at some point, many are instigated and supervised from a national level. In these countries, therefore, flood mitigation can be said to be implemented mainly through a combination of centralized and decentralized governance. Conversely, in the Netherlands, through the regulating and taxing competences of the regional water authorities, and, counterintuitively, in France, the primary responsibility for implementing these measures lies with local governments, which explains terms such as local or bottom-up governance, although in the Netherlands certain mitigation measures, such as the disconnection of rainwater, Room for the River, and the multilayered safety approach, have now also been institutionalized in national policies. Finally, Poland's implementation of flood mitigation is mainly supported by local and regional authorities.

To sum up, mitigation governance in the six countries can indeed be characterized as multilevel governance. According to our data, the actors involved perceive it to strike an appropriate balance, given the institutional structure and culture in the researched countries.

To conclude our review of this criterion, the examples of these six countries show that a balance between top-down and bottomup decision making can only be achieved if there is a clear division of responsibilities in a legal sense. Such a division is clearly present in Belgium, England, and the Netherlands. In countries in which there is no such division, like Poland, it is much more difficult to find governance arrangements enabling bottom-up decision making. On the other hand, when responsibilities are excessively divided, governance processes lose their consistency, and may create confusion, in particular for riparian owners or residents, who are therefore more reluctant to become involved. In several of our countries, it is also noticeable that a good balance between top-down and bottom-up in decision making can only be attained when a comprehensive overview of the mitigation strategy exists at the higher institutional levels. Within the EU Floods Directive, FRM plans are expected to facilitate coordination between all institutional stakeholders. To solve coordination problems and facilitate the involvement at local levels, there is a need for proactive attitudes at regional and national scales.

Finally, it is interesting to note that in many countries, mitigation is a sector in which there is still room for initiatives and front runners. In Poland, municipalities take an active role, thanks to some legal margins left to them. In the Netherlands, legislation leaves room for local initiatives. In France, mitigation is the least constrained of the various flood risk management strategies, and legislation leaves room for experimentation and local initiatives. 
Table 3. Characterization of the six researched countries on the degree to which local and/or multilevel governance is present.

\begin{tabular}{|c|c|}
\hline Country & Characterization \\
\hline Belgium & $\begin{array}{l}\text { Spatial planning and environmental departments of municipalities are becoming increasingly important; } \\
\text { In Flanders, the Flemish Environment Agency (VMM) at a regional scale encourages municipalities to take } \\
\text { mitigation measures, through the organization of lectures, etc. } \\
\text { For every building permit with a possible impact on the water system, municipalities have to ask supralocal } \\
\text { governments for advice on mitigation measures (water test), which can only be deviated from if reasons are } \\
\text { provided; } \\
\text { In Wallonia, flood mitigation measures are mainly advocated via river contracts, which operate at a subbasin } \\
\text { scale. Municipalities have the right to ask supralocal governments for advice when delivering a building permit, } \\
\text { but this is not an obligation; } \\
\text { Provincial and regional governments install water retention zones along watercourses. }\end{array}$ \\
\hline England & $\begin{array}{l}\text { The Environment Agency (EA) maintains a strategic overview of FRM for all types of flooding (Flood and } \\
\text { Water Management Act 2010), and has operational responsibility for managing risks from the main rivers, } \\
\text { reservoirs, estuaries, and the sea; } \\
\text { Lead local flood authorities (LLFAs) are responsible for developing and enacting local strategies for FRM for } \\
\text { ordinary watercourses (watercourses other than main rivers), surface water, and groundwater; } \\
\text { Internal drainage boards (IDBs) also have operational responsibilities for managing ordinary watercourses and } \\
\text { maintaining the drainage infrastructures within their internal drainage districts; The Highways Agency and water } \\
\text { companies also have responsibilities; } \\
\text { The above actors are collectively referred to as risk management authorities (RMAs) and have duties of } \\
\text { cooperation (established by the Flood and Water Management Act 2010). }\end{array}$ \\
\hline France & $\begin{array}{l}\text { Municipalities and Intercommunalités (a relatively new localized layer of government) are central, innovative } \\
\text { actors in flood mitigation, especially with regard to flood-proof housing; } \\
\text { Water-related institutions develop methodologies and knowledge; } \\
\text { Compared with other FRMSs, flood mitigation is not strictly regulated or framed. }\end{array}$ \\
\hline $\begin{array}{l}\text { The } \\
\text { Netherlands }\end{array}$ & $\begin{array}{l}\text { Local governments, in consultation with private stakeholders, are the actors who are setting up relatively new } \\
\text { mitigation measures, including green roofs, floating urbanization, etc.; } \\
\text { Municipalities, often in consultation with local water authorities, are the initiators of measures to decouple } \\
\text { rainwater from the sewerage system. Attempts are often made to encourage residents to take action as well, but } \\
\text { this has turned out to be difficult in many cases (OECD 2014). }\end{array}$ \\
\hline Poland & $\begin{array}{l}\text { Official agencies assume a limited role in flood mitigation; } \\
\text { Measures are often implemented by private actors on their own; the involvement of local communities, in } \\
\text { principle very possible, only occurs to a very limited extent. This has led to initiatives on the part of private actors } \\
\text { to install rainwater collectors in private gardens, leading to a (partial) disconnection of rainwater from the } \\
\text { sewerage system, thereby decreasing the flood hazard; } \\
\text { Some local governments have made attempts to offer incentives to those who do not use the main rainwater } \\
\text { sewerage system; } \\
\text { In the city of Poznan, a tax on impermeable coverings was introduced to reduce the amount of private land } \\
\text { covered with concrete. This decision was challenged in court, and the funds went to the overall municipal budget, } \\
\text { thereby limiting the effectiveness of this policy measure. }\end{array}$ \\
\hline Sweden & $\begin{array}{l}\text { Municipalities are the main actors initiating planning- and building-related mitigation measures. This is said to } \\
\text { aid the tailoring of measures (such as green infrastructures) to local conditions; } \\
\text { The National Board on Housing, Building and Planning has issued binding guidelines for climate adaptation } \\
\text { measures, prescribing, among other things, permeable materials on the land around buildings, local management } \\
\text { of storm-water, green roofs (to reduce runoff), overflow spillways on roofs, and schedules for cleaning wells; } \\
\text { Legislation on habitat protection, wetland restoration or development sometimes leads to so-called nonpurpose } \\
\text { mitigation measures. }\end{array}$ \\
\hline
\end{tabular}

Criterion II: Multiactor (formal and informal) networks, including active participation on the part of citizens

As Table 4 shows, the extent to which private actors, including citizens, participate in mitigation strategy varies from country to country, but it is still relatively limited in most of them. One initial distinction can be made between on-the-ground implementation of mitigation measures and participation in decision making.
With regard to on-the-ground implementation, in Belgium, England, the Netherlands, Sweden, and France, private actors (such as landowners) and residents install mitigation measures in housing. In the Netherlands, France, and England, also, in various local cases, we found examples of bottom-up, community-based initiatives. These seem to be part of an emerging trend, at least in Belgium, England, France, and the Netherlands (Alexander et al. 
Table 4. Characterization of the six researched countries on the degree in which private actors, including citizens, are involved in the flood mitigation strategy.

\begin{tabular}{|c|c|}
\hline Country & Characterization \\
\hline Belgium & $\begin{array}{l}\text { Private actors and residents are involved in installing mitigation measures (e.g., green roofs), but only to a limited } \\
\text { extent in mitigation decision making; } \\
\text { Citizens are consulted in the drafting of spatial plans (less intensive public participation). }\end{array}$ \\
\hline England & $\begin{array}{l}\text { Mitigation projects (like defense) are funded according to the partnership funding scheme implemented in } 2012 . \\
\text { Grant-in-Aid (GiA) must be supported by funding sourced at a local level, through local authorities, the private } \\
\text { sector, or civil society. The costs for the project are distributed across funding partners according to risk-sharing } \\
\text { arrangements and defined in a legally binding contract. }\end{array}$ \\
\hline France & $\begin{array}{l}\text { Involvement of residents in measures for adapting houses. Mitigation projects and vulnerability reduction for } \\
\text { houses and companies are funded through public/insurance funds. France has an established tradition of public } \\
\text { participation in planning matters: risk plans are submitted to public enquiry. }\end{array}$ \\
\hline The & Some localized community-based initiatives are present, set up by residents (such as Dakpark Rotterdam, a \\
\hline Netherlands & $\begin{array}{l}\text { multifunctional project that served inter alia to increase the amount of green space in the urban environment). } \\
\text { Other pilot projects with floating urbanization have been initiated, also at a niche level. In other cases, citizens } \\
\text { have opposed mitigation measures: for instance, the first water plaza in Rotterdam was greeted with considerable } \\
\text { public opposition and was reframed by some residents as a "drowning plaza for small children" (Biesbroek et al. } \\
\text { 2014). } \\
\text { More institutionalized forms of disconnecting rainwater from the sewer have now been included in national } \\
\text { policies (Kaufmann et al. 2016). }\end{array}$ \\
\hline Poland & $\begin{array}{l}\text { Involvement on the part of actors other that the water authorities is rare, although one successful example of this } \\
\text { is the case of the Domaszków-Tarchalice polder. In this polder, Wroclaw's WWF branch, together with the } \\
\text { Provincial Drainage, Irrigation and Infrastructure Authority, decided to remove parts of certain flood dikes to } \\
\text { form a polder into which water could flow naturally in the event of increased rainfall. Implementation of this } \\
\text { measure required local community involvement and initiated various stakeholders networks in which a leading } \\
\text { role was played by NGOs. }\end{array}$ \\
\hline Sweden & $\begin{array}{l}\text { Private actors and residents are involved in installing mitigation measures (such as green roofs), but only to a } \\
\text { limited extent in mitigation decision making. } \\
\text { Citizens are consulted on the drafting of spatial plans. } \\
\text { Stakeholders and NGOs are involved in nonpurpose mitigation measures, both as initiators and as participants in } \\
\text { the consultation processes. There is no evidence, however, that the mitigation strategy as such involves more or } \\
\text { less participation or community involvement than other measures for which this is a requirement. }\end{array}$ \\
\hline
\end{tabular}

2016, Kaufmann et al. 2016, Larrue et al. 2016, Mees et al. 2016). In these countries, measures to accommodate water, such as flood storage areas or dynamic retention zones, are mainly implemented by public authorities. In stark contrast, in Poland, participation by actors other than the water authorities is virtually nonexistent, although there are examples of pilot projects involving local communities (see Table 4).

In England in particular, a partnership approach to funding mitigation (and defense) projects has been in place since 2012 . This approach requires Grant-in-Aid (GiA), which is available through the Department for Environment, Food and Rural Affairs (DEFRA) and administered by the EA, supported by funding sourced at a local level though local authorities, the private sector, or civil society (DEFRA 2011). The costs of a project are thus distributed across funding partners according to risk-sharing arrangements and defined in a legally binding contract. This approach means that new types of actors with a financial stake in FRM can enter governance arrangements at a project level. Citizens' participation is also being actively promoted: for example, in Kingston-upon-Hull, a number of flood storage areas are currently being developed in the surrounding rural area to mitigate the risk of surface water flooding in the city, the largest of which is the Willerby and Derringham Flood Alleviation Scheme (WaDFAS). This project has engaged local citizens through parish meetings alongside more innovative means including a flood bus, which attended local events and gave the public an opportunity to discuss flood concerns and to debate the project in greater detail. Public exhibitions were also used to demonstrate flood modeling and to facilitate a dialogue between the public and the relevant risk management authorities. Public engagement activities have also helped the scheme to gain public acceptance. Engagement initiatives such as these are seen as standard practice in England (Alexander et al. 2016).

With regard to public participation in decision making, only Sweden and England seem to be at an advanced stage. In the case of Sweden, this can probably be explained because of its longstanding tradition of participation in planning processes. England also has a long-standing approach favoring citizens' engagement in decision making. In Belgium, the Netherlands, and France, a number of participation mechanisms, such as formal consultations on spatial plans are in place, but these must be characterized as less intensive forms of participation. Within the EU Floods Directive, public participation is now required when 
establishing FRM plans. More precisely, the title of Chapter V refers to the notions of information and consultation.

It emerges clearly from these six national examples that multiactor networks are facilitated where they are anticipated or promoted by institutional arrangements. For instance in England, efforts to increase community involvement in FRM are promoted through national policy, legislation, and established views of best practice. In other countries, there are specific tools to facilitate multiactor networks: river contracts in Belgium or Programmes d'Actions pour la Prévention des Inondations (PAPI) in France lead to the development of institutional networks at a river-basin scale.

Nonetheless, comparative analysis reveals a number of shared constraints to public participation in flood mitigation and barriers to increasing citizen involvement. This includes the lack of flood experience, little awareness of the flood risk, misperceptions of the risk, and lack of financial resources to support the implementation of property level mitigation measures. Participation by citizens sometimes initially arises out of conflictual situations. In most countries, it appears that it is difficult to involve the private sector, mainly (but not only) for financial/economic reasons. In England, a key objective of Partnership Funding (implemented in 2012) is to encourage public-private partnerships, yet to date, this has largely been delivered through the redistribution and diversification of public sector sources (NAO 2014, Alexander et al. 2016). Moreover, plans to attract private investors have been called into question, especially as only $£ 40$ million of the $£ 148$ million secured to date has come from sources beyond local government (EFRA 2015).

\section{Criterion III. Flexibility in governance arrangements enabling} mitigation measures to be tailored to local conditions

When considering mitigation measures in the six countries, we noticed that governance arrangements in all of them have enabled the development of innovative and adaptive proposals adapted to local contexts that take advantage of local assets and are consistent at various levels.

More generally, mitigation measures can address three territorial scales, which have not yet been fully addressed in all six countries. They relate to the adaptation of cities at a single property (house or building) scale, and we have found measures for property adaptation in Sweden and England (minimum floor levels), vulnerability reduction measures in France, adapted housing in the Netherlands (flood-proof buildings), and property resistance and resilience measures in England. We also found measures to better adapt neighborhoods to flood risk, examples being the construction of permeable paving and sustainable drainage approaches, which prevent pluvial floods and urban runoff, in England, the Netherlands, and Sweden. In the Dutch case in particular, there is ample room for local governmental actors to initiate mitigation measures. Our interviews revealed examples of situations in which mitigation measures would provide a potential addition to flood management (e.g., in areas not protected by dikes it would make sense to put power facilities on heights) without them being implemented. This suggests that there is more room for implementing mitigation measures than is used in practice, although the precise amount of room is very hard to quantify. Moreover, citizens' groups, private companies, or NGOs may also seek to collaborate with municipalities. The focus on local-level solutions and the involvement of multiple actors seems in itself to facilitate flexible approaches.
Finally, mitigation measures to control water flows address the flood issue at a broader level; these include dynamic retention areas and flood storage areas. These measures are often embedded within not only multifunctional projects, i.e., river restoration projects address water, biodiversity, and flood issues, but potentially also economic issues, i.e., the diversification of land use near rivers. In France and the Netherlands, meanders are (re) created in rivers under the Water Framework Directive (WFD; Bonnefond and Fournier 2013, de Boer 2014). The cases of Belgium and England also offer examples of river restoration projects with mitigation objectives. In Sweden and Poland, initiatives for the preservation of wetlands are also considered to contribute to flood mitigation as a corollary effect. Today, these three territorial scales are all addressed in the six countries, even though they may still be at an emerging stage, for instance, in France (scale of neighborhoods) and Poland (scale of single housing).

The analysis highlights the importance of three supporting factors. First, formal divisions of responsibilities and the granting of leeway to local governments especially facilitate the development of mitigation measures locally, at the most significant scale. As we have seen in Sweden, mitigation measures can also be well-adapted to local conditions when they are not strictly defined as a flood risk strategy and contribute first to improvements in the quality of rivers (here, mitigation is a byproduct). In France and Belgium, mitigation measures are tailored to local conditions in that they are defined as a part of cohesive projects at a river basin scale. In Belgium, the flood issue is just one aspect of the river contract, like biodiversity or water quality. In Poland, thanks to the involvement of international NGOs, a more proenvironmental approach is enabling the preparation of local measures that not only contribute to nature or landscape conservation, but also have a secondary effect on flood mitigation.

Criterion IV. Governance arrangements support management at the appropriate scale of the problem (for example, fluvial FRM should be managed according to hydrological scales, on a catchment as opposed to administrative basis)

The EU Floods Directive (FD) prescribes the implementation of FRM plans at the appropriate scale. This requires either organizations at this level, or intense coordination and cooperation among authorities at other government levels. In most studied countries, coordination between the authorities and the various stakeholders involved in mitigation exists at a catchment scale (in Belgium, England, France, the Netherlands, and Sweden).

In Wallonia (Belgium), effective stakeholder coordination at a catchment level is provided by river contracts, which have become active promoters of mitigation measures within their catchment areas. In France, since the beginning of the 2000s, all stakeholders, from all institutional levels, public or private, are coordinated at the catchment scale within the framework of the PAPI. It is also of interest that PAPIs favor the implementation of mitigation measures over and above any other type of flood management measure.

In England, it is the type of flood risk that determines the appropriate hydrological scales and the actors best placed to address the problem: for instance, fluvial flooding on the main rivers is managed at a catchment scale by the Environment Agency 
(EA), and surface-water flooding is managed at a local scale by LLFAs. The strategic responsibilities of the EA ensure that decisions made at a local scale are not detrimental to other areas and also help maintain a degree of national consistency in FRM. Indeed, local FRM plans must be consistent with the national strategy proposed by the EA. One crucial feature of English flood risk governance, however, is that it encourages locally tailored approaches to emerge.

In the Netherlands, floods are also managed at various levels. Regional water authorities are responsible for flood risks from local waters and for the majority of the primary flood defense constructions, which protect against flooding of the sea and the rivers. Pluvial flooding is generally handled by municipalities, often in collaboration with the regional water authorities, which are responsible for flood risks from local waters and for parts of the main rivers (Kaufmann et al. 2016). The Ministry of Infrastructure and the Environment conducts a strategic overview of flood risk management in the country as a whole while the regional water authorities are managing most of the primary flood constructions like dunes and dikes, whereas the Office of Public Works is the water authority for those water management structures that are not managed by the regional water authorities. For instance, both the Dutch Delta Program and the aforementioned Room for the River Program must be considered to be multilevel governance programs, with a coordinating role for national level actors (Delta Commissie 2008, Delta Programme 2013). We can conclude that by and large, mitigation strategies are being implemented at the appropriate levels.

In Sweden, it is the type of floods that also determines the relevant scale for action. Fluvial floods are usually associated with heavy rains, melting snow, or ice plugs. The consequences are generally not dramatic, and the floods are managed by the (impacted) local level. Pluvial floods have become more common in recent times. They affect relatively small geographical areas, and although the local effects can be significant in financial terms, they do not normally have an impact on society as a whole. Flooding as a result of storm water and sewerage systems not able to deal with heavy rains is primarily dealt with by the municipalities, which are also responsible for developing systems and implementing mitigation measures.

Most countries make use of the hydrological scale to tackle the issue and have settled institutions or planning documents consistent with river catchments. In England, there are key planning documents at a basin level (catchment flood management plans, shoreline management plans, and river basin management plans). In France (PAPI) or Belgium (river contracts), mitigation measures are also defined at a river basin level. On a larger scale, in Poland, the regional water management boards are a catchment-based body. In the Netherlands, a formal division of responsibilities facilitates the definition of measures at the most relevant scale. For some countries, like Sweden, the WFD and FD also play a role in the preparation of flood management plans that are consistent at a river basin level.

\section{Criterion V. Opportunities for experimentation and for social and institutional learning}

Finally, in all six countries, flood mitigation appears to be a strategy that is well-suited to experimentation and learning, and evidence of this can be found in the various countries involved in our research.
In general, mitigation measures are frequently presented as experimental in the various countries. In France, this is clearly the case in Nevers, when the city authorities plan to lower the dikes and allow water to flow along a water route (chemin de l'eau) through neighborhoods. The water plazas in Rotterdam, which are rainwater retention measures, are also considered to be experimental. In Delft and Rotterdam, we see examples of floating houses. Within the framework of the 2005 Sigma Plan, which is intended to protect the Belgian Scheldt estuary from flooding, a new type of tidal flood control area has been developed. In Sweden, it has been stressed that because of the effects of mitigation measures in terms of how much water will actually be accommodated, municipalities may refrain from relying too heavily on such measures. Mitigation measures also offer the chance to adapt them to changing flood risks. The Belgian Sigma Plan, for example, defines areas that have not yet been developed a flood retention zones, but which may become such in the future when the flood risks have increased even further. Learning from experience as well as from research programs is a crucial feature of English flood risk governance. For instance, measures to mitigate surface water flooding have gained momentum following the floods of the summer of 2007 and the subsequent independent inquiry (Pitt 2008). These lessons were addressed through the implementation of new legislation in the form of the Flood and Water Management Act 2010 and subsequent revisions to the National Planning Policy Framework.

To conclude on this criterion, mitigation measures are still new and experimental in most countries. In all six, there is clearly a willingness to experiment, and it is through this strategy that most front-running initiatives have been identified. Nontraditional institutions also play a role in those innovations (as in Poland). Institutional learning is also very much promoted through mitigation measures, even though questions remain about the optimal ways to draw lessons from these experiments.

\section{DISCUSSION}

Table 5 essentially maps the distance between current governance arrangements and aspired forms of adaptive governance within each of the studied countries. First of all, flood mitigation appears to be the main strategy by means of which pilot projects, experimentation, and learning from experimenting on social, institutional, and technical issues are most common and receive the most encouragement, and we find examples of it in all our countries (criterion V). This observation can be attributed to the emerging nature of flood mitigation within most countries (except England). Learning is inherently promoted as new types of actors or responsibilities are devolved to local scale actors. All these factors make the development of local knowledge-based legitimacy highly desirable. A crucial point to emphasize is that the capacity to adapt does not necessarily equate to the eradication of flooding; in fact, floods may still occur yet a country can be described as incredibly adaptive. This is the case in England, in which successive winter flooding in 2013/2014 and 2015/2016 have prompted critical reviews of the FRM approach, highlighting both strengths and weaknesses, as well as opportunities to improve (e.g., the National Flood Resilience Review was launched in February 2016). 
Table 5. Summary of criteria assessments by country (low/medium/high).

\begin{tabular}{|c|c|c|c|c|c|c|}
\hline & Belgium & England & France & $\begin{array}{l}\text { The } \\
\text { Netherlands }\end{array}$ & Poland & Sweden \\
\hline $\begin{array}{l}\text { Multilevel governance, with the } \\
\text { right balance between top-down } \\
\text { and bottom-up decision making }\end{array}$ & High & $\begin{array}{l}\text { Medium/ } \\
\text { High }\end{array}$ & Medium & $\begin{array}{l}\text { Medium/ } \\
\text { High }\end{array}$ & Low & Medium \\
\hline $\begin{array}{l}\text { Multiactor (formal and } \\
\text { informal) networks, including } \\
\text { active participation on the part } \\
\text { of citizens }\end{array}$ & Medium & High & Low & Low/Medium & Low & Low \\
\hline $\begin{array}{l}\text { Flexibility in governance } \\
\text { arrangements enabling } \\
\text { mitigation measures tailored to } \\
\text { local conditions }\end{array}$ & Medium & High & Medium & High & Low & Medium/High \\
\hline $\begin{array}{l}\text { Governance arrangements } \\
\text { support management at the } \\
\text { appropriate scale of the problem }\end{array}$ & $\begin{array}{l}\text { Low/ } \\
\text { Medium }\end{array}$ & High & $\begin{array}{l}\text { Medium/ } \\
\text { High }\end{array}$ & $\begin{array}{l}\text { Medium/ } \\
\text { High }\end{array}$ & Low/Medium & Low/Medium \\
\hline $\begin{array}{l}\text { Opportunities for } \\
\text { experimentation and for social } \\
\text { and institutional learning }\end{array}$ & High & High & $\begin{array}{l}\text { Medium/ } \\
\text { High }\end{array}$ & $\begin{array}{l}\text { Medium/ } \\
\text { High }\end{array}$ & Medium & High \\
\hline
\end{tabular}

Second, all countries appear to have progressively developed multilevel governance systems, albeit to varying degrees, e.g., Belgium, England, and the Netherlands are highly established, whereas, this is low in Poland. The differences may be related to different contextual conditions, particular with regard to legal and administrative frameworks. Multilevel governance appears to be facilitated when there is a clear, legally established division of responsibilities as in England and the Netherlands. When this division is not created through legislation, even though attempts are made by local actors, as in Poland, they remain very much constrained.

Third, flexibility in governance arrangements is required to enable mitigation measures to be tailored to local conditions. However, there remains room for improvement. Although there is significant leeway for local governments and private parties in England, the Netherlands, and Sweden, this is not the case elsewhere and legally rigid frameworks can act as a constraint.

The fit between scales of governance and the hydrological scale of the flood problem is not always perfectly matched. In some countries, the basin level is the level for planning measures to mitigate fluvial flooding, as in England and France (PAPI). Certain key stakeholders are also organized at a basin level, as in France, with Etablissements Publics Territoriaux de Bassin (EPTB). In others, Poland, Belgium, and even the Netherlands and Sweden, traditional administrative boundaries can present an obstacle to the potential implementation of measures at an appropriate scale. In both Sweden and the Netherlands for instance, although the boundaries of regional water authorities are related to hydrological boundaries, those of municipalities and provinces are not. This issue is even more complex for countries such as the Netherlands or Belgium, which have to deal with international river basins.

Last, in all six countries, there is a similar struggle to involve citizens in FRM, even in England, in which incentives and experiments are most advanced. People in England and Sweden are responsible for their own safety and there is no national solidarity. However, even in these countries with advanced initiatives, public participation still remains complicated. This may be related to financial and cultural factors, but is also citizens' knowledge of flood risk. Measures implemented as a part of the mitigation strategy reflect new ways of dealing with floods, i.e., based on local contexts, local initiatives, and multifunctionality, however, overall, flood mitigation governance is yet to be fully representative of adaptive governance and a number of criteria are fulfilled better than others (experimentation/social and institutional learning, multilevel governance). In some regards, this may constrain efforts to enhance societal resilience to flooding in the future.

Our findings suggest that the implementation of the mitigation strategy is conducive to realizing adaptive governance, although there is still room for improvement. To the extent that adaptability is one of the key features of resilience, we argue that this development is enhancing societal resilience to flooding.

\section{CONCLUSION}

We engaged with the question of whether, to what extent, and how the increasing implementation of the mitigation strategy in Belgium, England, France, the Netherlands, Poland, and Sweden is facilitating shifts toward aspired forms of adaptive governance.

We have shown that flood mitigation in the studied countries presents features of adaptive governance to varying degrees. In England, the Netherlands, and Belgium, the strategy appears to be more highly developed and mainstream: it is part of a diversified FRM that tends toward a more balanced strategy intended to produce greater resilience in the face of flood risks. In France, Sweden, and Poland, on the other hand, flood mitigation measures and initiatives are highly localized and can be viewed as the exception rather than the rule (with a very low degree of institutionalization). Their development requires 
greater resources, i.e., legal, financial, and cognitive. Strengthening them in a flood risk governance context remains a challenge, although there have been promising developments. In Sweden and Poland, this strategy has not been deliberately implemented because it is a side effect of different activities. However, the presence of forward-looking municipalities with proactive policy entrepreneurs in the Netherlands, successful examples in England, incentives in France and Belgium, the rising role of NGOs in Poland, and the development of specific knowledge in Sweden all constitute drivers for implementing adaptive forms of flood governance and promoting mitigation measures such as these in European countries.

To conclude on the capacity of mitigation strategy to contribute to improved resilience to flood risk in the six countries, it can be said that, compared to other strategies, mitigation is the strategy in which most of the characteristics of adaptive governance may be found.

This framework has wider application potential and could be applied to the study of other FRM strategies and comparisons therein (Hegger et al. 2014). Such research could shed light on how certain aspects of FRM could be improved and on the opportunities/barriers to implementing adaptive modes of governance. In the context of future uncertainty and projected increases in flood risk due to shifts in climate, land use, and socioeconomic conditions, this is a necessary step forward in terms of informing recommendations to enhance societal resilience to flooding.

Responses to this article can be read online at: http://www.ecologyandsociety.org/issues/responses. $\mathrm{php} / 8991$

\section{Acknowledgments:}

This article has been written in the framework of the STARFLOOD project, which belongs to the European Union's Seventh Framework Programme for Research, Technological Development and Demonstration. This research has received funding from the European Commission under grant agreement no. 308364.

\section{LITERATURE CITED}

Adger, W. N. 2006. Vulnerability. Global Environmental Change 16:268-281. http://dx.doi.org/10.1016/j.gloenvcha.2006.02.006

Adger, W. N., T. P Hughes, C. Folke, S. R. Carpenter, and J. Rockstroöm. 2005. Social-ecological resilience to coastal disasters. Science 309:1036-1039. http://dx.doi.org/10.1126/ science. 1112122

Aerts, J. C. J. H., W. Botzen, A. van der Veen, J. Krykow, and S. Werners. 2008. Dealing with uncertainty in flood management through diversification. Ecology and Society 13(1):41. [online] URL: http://www.ecologyandsociety.org/vol13/iss1/art41/ http:// dx.doi.org/10.5751/es-02348-130141

Alexander, M., S. Priest, A. P. Micou, S. Tapsell, C. Green, D. Parker, and S. Homewood. 2016. Analysing and evaluating flood risk governance in England - enhancing societal resilience through comprehensive and aligned flood risk governance. STAR-FLOOD Consortium, Flood Hazard Research Centre, Middlesex University, London, UK. [online] URL: http://www. preventionweb.net/publications/view/48467

Aligica, P. D. 2006. Institutional and stakeholder mapping: frameworks for policy analysis and institutional change. Public Organization Review 6:79-90. http://dx.doi.org/10.1007/s11115-006-6833-0

Biesbroek, G. R., C. A. J. M. Termeer, J. E. M. Klostermann, and P. Kabat. 2014. Rethinking barriers to adaptation: mechanismbased explanation of impasses in the governance of an innovative adaptation measure. Global Environmental Change 26:108-118. http://dx.doi.org/10.1016/j.gloenvcha.2014.04.004

Bonnefond, M., and M. Fournier. 2013. Maîtrise foncière dans les espaces ruraux. Un défi pour les projets de renaturation des cours d'eau. Economie Rurale 334:55-68. http://dx.doi. org/10.4000/economierurale. 3908

Brody, S. D., S. Zahran, W. E. Highfield, S. P. Bernhardt, and A. Vedlitz. 2009. Policy learning for flood mitigation: a longitudinal assessment of the community rating system in Florida. Risk Analysis 29(6):912-929. http://dx.doi.org/10.1111/j.1539-6924.2009.01210. $\underline{\mathrm{X}}$

Brooks, N., W. N. Adger, and P. M. Kelly. 2005. The determinants of vulnerability and adaptive capacity at the national level and the implications for adaptation. Global Environmental Change 15:151-163. http://dx.doi.org/10.1016/j.gloenvcha.2004.12.006

Brosius, J. P., A. L. Tsing, and C. Zerner, editors. 2005. Communities and conservation: histories and politics of community-based natural resource management. Altamira, New York, New York, USA.

Chaffin, B. C., H. Gosnell, and B. A. Cosens. 2014. A decade of adaptive governance scholarship: synthesis and future directions. Ecology and Society 19(3):56. http://dx.doi.org/10.5751/ es-06824-190356

Cosens, B. A., and M. K. Williams. 2012. Resilience and water governance: adaptive governance in the Columbia River basin. Ecology and Society 17(4):3. http://dx.doi.org/10.5751/ES-04986-170403

Davoudi, S., K. Shaw, L. J. Haider, A. E. Quinlan, G. D. Peterson, C. Wilkinson, H. Fünfgeld, D. McEvoy, L. Porter, and S. Davoudi. 2012. Resilience: a bridging concept or a dead end? "Reframing" resilience: challenges for planning theory and practice interacting traps: resilience assessment of a pasture management system in Northern Afghanistan urban resilience: what does it mean in planning practice? Resilience as a useful concept for climate change adaptation? The politics of resilience for planning: a cautionary note. Planning Theory and Practice 13:299-333. http:// dx.doi.org/10.1080/14649357.2012.677124

De Boer, C. 2012. Contextual water management. A study of governance and implementation processes in local stream restoration projects. Dissertation, University of Twente, Enschede, The Netherlands. [online] URL: http://doc.utwente. $\underline{\text { n1/81724/ }}$

Department of Environment, Food and Rural Affairs (DEFRA). 2011. Flood and coastal resilience partnership funding: an 
introductory guide. Environment Agency, Bristol, UK. [online] URL: https://www.gov.uk/government/uploads/system/uploads/ attachment data/file/182524/flood-coastal-resilience-intro-guide. pdf

Department of Environment, Food and Rural Affairs (DEFRA) and Environment Agency. 2014. Working with natural processes to reduce flood risk: a research and development framework. $\mathrm{R}$ and D Framework Science Report. Report-SC130004/R2. Environment Agency, Bristol, UK. [online] URL: https://www.gov.uk/ government/publications/working-with-natural-processes-to-reduceflood-risk-a-research-and-development-framework

De Graaf, R., N. van de Giesen, and F. van de Ven. 2009. Alternative water management options to reduce vulnerability for climate change in the Netherlands. Natural Hazards 51 (3):407-422. http://dx.doi.org/10.1007/s11069-007-9184-4

Delta Commissie. 2008. Samen werken met water: een land dat leeft, bouwt aan zijn toekomst. Bevindingen van de Deltacommissie 2008. Delta Committee, The Hague, The Netherlands. [online] URL: http://www.deltacommissie.com/doc/2008-12-10\%20publieksversie. pdf

Delta Programme. 2013. Werk aan de delta, kansrijke oplossingen voor opgaven en ambities. Delta Programme, The Hague, The Netherlands. [online] URL: https://www.deltacommissaris.nl/ documenten/publicaties/2013/09/17/deltaprogramma-2014

Dietz, T., E. Ostrom, and P. C. Stern. 2003. The struggle to govern the commons. Science 302:1907-1912. http://dx.doi.org/10.1126/ science.1091015

Environment, Food and Rural Affairs Committee (EFRA). 2015. Defra performance in 2013-14. Eighth report of session 2014-15. Stationery Office Limited, London, UK. http://www. publications.parliament.uk/pa/cm201415/cmselect/cmenvfru/802/802. pdf

Ek, K., S. Goytia, M. Pettersson, and E. Spegel. 2016. Analysing and evaluating flood risk governance in Sweden: adaptation to climate change? STAR-FLOOD Consortium, Utrecht, The Netherlands. [online] URL: http://ltu.diva-portal.org/smash/get/ diva2:995169/FULLTEXT01.pdf

Folke, C. 2006. Resilience: the emergence of a perspective for social-ecological systems analyses. Global Environmental Change 16:253-267. http://dx.doi.org/10.1016/j.gloenvcha.2006.04.002

Folke, C., S. R. Carpenter, B. Walker, M. Scheffer, T. Chapin, and J. Rockström. 2010. Resilience thinking: integrating resilience, adaptability and transformability. Ecology and Society 15(4):20. [online] URL: http://www.ecologyandsociety.org/vol15/iss4/ $\underline{\operatorname{art} 20 /}$

Folke, C., T. Hahn, P. Olsson, and J. Norberg. 2005. Adaptive governance of social-ecological systems. Annual Review of Environment and Resources 30:441-473. http://dx.doi.org/10.1146/ annurev.energy.30.050504.144511

Gallopín, G. C. 2006. Linkages between vulnerability, resilience, and adaptive capacity. Global Environmental Change 16:293-303. http://dx.doi.org/10.1016/j.gloenvcha.2006.02.004

Gunderson, L., and S. S. Light. 2006. Adaptive management and adaptive governance in the everglades ecosystem. Policy Science 39:323-334. http://dx.doi.org/10.1007/s11077-006-9027-2
Hegger, D. L. T., P. J. P. Driessen, C. Dieperink, M. Wiering, G. T. T. Raadgever, and H. F. M. W. van Rijswick. 2014. Assessing stability and dynamics in flood risk governance. Water Resources Management 28:4127-4142. http://dx.doi.org/10.1007/s11269-014-0732$\underline{x}$

Hegger, D. L. T., C. Green, P. P. J. Driessen, M. H. N Bakker, C. Dieperink, A. Crabbé, K. Deketelaere, B. Delvaux, C. Suykens, J.-C. Beyers, M. Fournier, C. Larrue, C. Manson, W. van DoornHoekveld, H. F. M. W van Rijswick, Z. W. Kundzewicz, and S. Goytia Casermeiro. 2013. Flood risk management in Europe: similarities and differences between STAR-FLOOD consortium countries. STAR-FLOOD Consortium, Utrecht, The Netherlands. [online] URL: http://dspace.library.uu.nl/handle/1874/314882

Huitema, D., E. Mostert, W. Egas, S. Moellenkamp, C. PahlWostl, and R. Yalcin. 2009. Adaptive water governance: assessing the institutional prescriptions of adaptive (co-)management from a governance perspective and defining a research agenda. Ecology and Society 14(1):26. [online] URL: http://www.ecologyandsociety. org/vol14/iss1/art26/ http://dx.doi.org/10.5751/es-02827-140126

Innocenti, D., and P. Albrito. 2011. Reducing the risks posed by natural hazards and climate change: the need for a participatory dialogue between the scientific community and policy makers. Environmental Science and Policy 14:730-733. http://dx.doi. org/10.1016/j.envsci.2010.12.010

Kaufmann, M., W. J. van Doorn-Hoekveld, H. K. Gilissen, and H. F. M. W. van Rijswick. 2016. Analysing and evaluating flood risk governance in the Netherlands: drowning in safety? STARFLOOD Consortium, Utrecht, The Netherlands. [online] URL: http://www.preventionweb.net/publications/view/48498

Larrue, C., S. Bruzzone, L. Lé;vy, M. Gralepois, T. Schellenberger, J.-B. Trémorin, M. Fournier, C. Manson, and T. Thuilier. 2016. Analysing and evaluating flood risk governance in France: from state policy to local strategies. STAR-FLOOD Consortium, Tours, France. [online] URL: http://climate-adapt.eea.europa.eu/ metadata/publications/analysing-and-evaluating-flood-risk-governancein-france-from-state-policy-to-local-strategies

Matczak, P., J. Lewandowski, A. Choryński, M. Szwed, and Z. W. Kundzewicz. 2016. Flood risk governance in Poland: looking for strategic planning in a country in transition. STAR-FLOOD Consortium, Utrecht, The Netherlands. [online] URL: $\underline{\text { http:// }}$ www.preventionweb.net/publications/view/48527

Mees, H., C. Suykens, J.-C. Beyers, A. Crabbé, B. Delvaux, and K. Deketelaere. 2016. Analysing and evaluating flood risk governance in Belgium. Dealing with flood risks in an urbanised and institutionally complex country. STAR-FLOOD Consortium, University Antwerp, KU Leuven, Belgium. [online] URL: $\underline{\text { http:// }}$ www.preventionweb.net/publications/view/48508

Mostert, E., M. Craps, and C. Pahl-Wostl. 2008. Social learning: the key to integrated water resources management? Water International 33(3):293-304. http://dx.doi.org/10.1080/02508060$\underline{802275757}$

National Audit Office (NAO). 2014. Strategic flood risk management. HC 780, Session 2014-15, 5th November 2014. Department for Environment, Food and Rural Affairs and Environment Agency, Bristol, UK. http://www.nao.org.uk/wpcontent/uploads/2014/11/Strategic-flood-risk-management.pdf 
Organisation for Economic Co-operation and Development (OECD). 2014. Water governance in the Netherlands: fit for the future? OECD Studies on Water. OECD Publishing, Paris, France. http://dx.doi.org/10.1787/9789264102637-en

Pahl-Wostl, C., J. Sendzimir, P. Jeffrey, J. Aerts, G. Bergkamp, and K. Cross. 2007. Managing change toward adaptive water management through social learning. Ecology and Society 12 (2):30. http://dx.doi.org/10.5751/es-02147-120230

Pitt, M. 2008. Learning lessons from the 2007 floods. Pitt Review. Cabinet Office, London, UK.

Raadgever, G. T., E. Mostert, N. Kranz, E. Interwies, and J. G. Timmerman. 2008. Assessing management regimes in transboundary river basins: do they support adaptive management? Ecology and Society 13(1):14. http://dx.doi. org/10.5751/es-02385-130114

Smit, B., and J. Wandel. 2006. Adaptation, adaptive capacity and vulnerability. Global Environmental Change 16:282-292. http://dx. doi.org/10.1016/j.gloenvcha.2006.03.008

United Nations Office for Disaster Risk Reduction (UNISDR). 2005. Hyogo framework for action 2005-2015: building the resilience of nations and communities to disasters. Extract from the final report of the World Conference on Disaster Reduction. United Nations Office for Disaster Risk Reduction, Geneva, Switzerland. [online] URL: http://www.unisdr.org/we/inform/publications/1037

Van den Brink, M., C. Termeer, and S. Meijerink. 2011. Are Dutch water safety institutions prepared for climate change? Journal of Water and Climate Change 2(4):272-287. http://dx.doi. org/10.2166/wcc.2011.044

Walker, B., C. S. Holling, S. R. Carpenter, and A. Kinzig. 2004. Resilience, adaptability and transformability in social-ecological systems. Ecology and Society 9(2):5. [online] URL: http://www. ecologyandsociety.org/vol9/iss2/art5/ http://dx.doi.org/10.5751/ es-00650-090205

Weber, E. P. 2003. Bringing society back in: grassroots ecosystem management, accountability, and sustainable communities. MIT Press, Cambridge, Massachusetts, USA. 